\title{
Construção de uma taxonomia sobre o entendimento do conceito científico de densidade baseada na noção de Perfil Epistemológico
}

\author{
Construction of an Epistemological Profile-based taxonomy for the \\ understanding of the scientific concept of density
}

\author{
Viviane Florentino de Melo'; Amanda Amantes² ${ }^{2}$ Rodrigo Drumond Vieira ${ }^{3}$
}

1 Doutoranda em Ensino, Filosofia e História das Ciências (UFBa), Universidade Federal da Bahia, Salvador, Bahia, Brasil vivianefm@ufba.br, / https://orcid.org/0000-0003-0152-2049

2 Doutora em Educação (UFMG), Universidade Federal da Bahia, Salvador, Bahia, Brasil - amandaamantes@gmail.com,/ https://orcid.org/0000-0003-1678-9870

3 Doutor em Educação (UFMG), Universidade Federal Fluminense, Niterói, Rio de Janeiro, Brasil - rodrumond@ gmail.com, / https://orcid.org/0000-0002-8063-4008

\section{Recebido em Julho/2018. Publicado em Abril/2020}

\section{Palavras-chave:}

Perfil Epistemológico.

Conceito Científico de densidade. Taxonomia.

RESUMO: Neste estudo apresentamos a elaboração de uma taxonomia para o conceito científico de densidade baseada na noção de perfil epistemológico de Bachelard. Para tanto, explicitamos as diferentes facetas que o conceito assume nas doutrinas filosóficas do empirismo e do racionalismo e elencamos os entendimentos referentes aos conteúdos escolares de densidade abordados no ensino médio na disciplina de Química. A hierarquia para cada doutrina foi constatada empiricamente por meio da aplicação de um questionário para 38 estudantes do ensino médio de um colégio federal da região metropolitana de Salvador que já haviam estudado o conteúdo, a coleta ocorreu no final do ano de 2017. A partir das respostas analisadas, obtivemos parâmetros que orientaram a construção de uma taxonomia para ser utilizada na análise do entendimento sobre o conceito de densidade na disciplina de Química. A construção da taxonomia neste estudo e a explicitação hierárquica dos entendimentos sobre densidade podem também informar a construção de materiais didáticos direcionados à prática docente, assim com promover um esclarecimento sobre como os estudantes entendem o conceito científico de densidade.

\section{Keywords:}

Epistemological Profile. Scientific Concept of Density.Taxonomy.
ABSTRACT: In this study we drawn from Bachelard's approach on epistemological profile to present a taxonomy for the concept of density. For that, we identified the different facets the concept assume into the philosophical doctrines of empiricism and rationalism, and we list the understandings referring to the school contents of density addressed at high school in the discipline of Chemistry. The hierarchy for each doctrine was validated empirically by applying a questionnaire to 38 high school students who had already studied the content. The survey assembles took place at the end of 2017, in a Federal High School in the Metropolitan area of Salvador. Based on the analyzed answers, we obtained parameters that guided the construction of taxonomy to be used in the analysis of the students' understanding of the concept of density in the discipline of Chemistry. The construction of the taxonomy in this study can also inform the construction of didactic materials aimed at informing the teaching practice and to promote more understanding of how the students understand the scientific concept of density. 


\section{INTRODUÇÃO}

Aprender conteúdos de ciências é um processo que subtende entendimento sobre conceitos científicos formais, visto que esses conceitos são os eixos estruturadores do currículo da ciência ensinada na escola (AL-TARAWNEH, 2016). No Brasil, a importância do ensino de conceitos é citada nas orientações curriculares para o ensino médio:

A grande importância da área de Ciências da Natureza, Matemática e suas Tecnologias no desenvolvimento intelectual do estudante do ensino médio está na qualidade e na quantidade de conceitos, aos quais se busca dar significado nos quatro componentes curriculares: Física, Química, Biologia e Matemática. (BRASIL, 2006, p.102)

São os conceitos que nos possibilitam dar sentido ou significado a um fato, relacionando-o dentro de uma rede de significados que explicam por que tais fatos ocorrem e que consequências eles têm (POZO; CRESPO, 2006). Em suas formas mais simples, os conceitos podem ser expressos por uma única palavra ou também podem representar um conjunto de ideias que podem ser descritas com algumas palavras (ZIRBEL, 2006).

Vários autores se debruçaram acerca do processo de aprendizado dos conceitos, (PIAGET, 1930; PIAGET; INHELDER, 1974, POZO; CRESPO, 2006; ZIRBEL, 2006; HASHWEH, 2015), visto que os conceitos são centrais no processo de dedução e auxiliam na explicação de ideias complexas dentro de uma estrutura de representação particular (ZIRBEL, 2006).

Zirbel (2006) aponta que dois conceitos podem ser combinados para formar uma terceira estrutura representacional. Cita como exemplo a "densidade", que é a "matéria" por "volume", ou seja, um conceito que é representado por apenas uma palavra, mas que é fruto da razão de dois outros conceitos.

Hashweh (2015) esclarece que o conceito de densidade levou séculos para ser concebido na forma como o conhecemos, e assim como Zirbel (2006), salienta que o conceito em si é parte de um sistema conceitual que incluem muitos conceitos interligados. Ele explica que qualquer propriedade intensiva ${ }^{1}$, como a densidade, "inclui alguns pressupostos sobre a natureza da matéria, especificamente os pressupostos sobre a continuidade e homogeneidade, e a suposição associada de que a propriedade intensiva é invariante sob múltiplas divisões do todo em partes" (HASHWEH, 2015, p. 03, tradução dos autores).

Dentro da Química, densidade é um conceito muito importante, utilizado para caracterizar substâncias, por exemplo. Contudo, seu ensino tem se pautado muito fortemente em uma única faceta desse conceito. Hawkes (2004) aponta que muitos alunos acreditam que 
a densidade é o resultado da operação aritmética da massa dividida pelo volume. O autor aponta que isso os impede de compreender a parte qualitativa da química, visto que o conceito de densidade é pelo menos tão importante quanto seu cálculo ou medição.

Em nosso trabalho, consideramos que o uso da equação que permite efetuar o cálculo da densidade é uma faceta do conceito, e que a parte apontada por Hawkes, como qualitativa, diz respeito à outra faceta.

Outra pesquisa que se debruçou sobre o aprendizado dos estudantes sobre densidade, essa no âmbito brasileiro, foi a de Rossi et. al., (2008). Seu estudo envolveu a participação de várias professoras de Química e de 440 estudantes de ensino médio e superior. Por meio de um questionário composto por seis questões, as autoras procuraram refletir sobre o que se ensina e o que se aprende sobre densidade no processo de escolarização.

No questionário utilizado no estudo havia duas questões nas quais os alunos eram convidados a fazer uma autoavaliação acerca de seu conhecimento sobre o conceito, uma antes de resolver as questões de densidade propriamente ditas e outra após quatro questões sobre o conteúdo.

Com relação à autoavaliação dos estudantes, as autoras afirmam que a maioria deles considerou que sabia muito ou tudo sobre densidade, contudo, apenas 54\% destes acertaram mais da metade do teste. Após a realização do teste, $44 \%$ mantiveram sua autoavaliação, fato que evidencia que eles não notaram seus erros ou apresentaram dúvidas quanto as suas concepções.

Como um dos resultados sobre as questões acerca da densidade, Rossi et. al., (2008) apontam a relação direta que os estudantes estabelecem entre o conceito de densidade e sua expressão matemática. As autoras enfatizam que por semelhança dos termos envolvidos, essa associação gera um paralelo equivocado com concentração. Ademais, o estudo detectou "a dificuldade na percepção do caráter intensivo da densidade e a falta de consideração das interações moleculares e polaridade para explicar a imiscibilidade de algumas substâncias" (ROSSI et. al., 2008, p. 01)

As autoras, concluíram que o conteúdo de densidade tem sido abordado com uma supervalorização das equações matemáticas, fato que elas afirmam acarretar graves problemas para o aprendizado dos alunos, inclusive no ensino superior. Ademais, elas consideram que tratar em momentos distintos os conceitos de densidade, interações moleculares e polaridade, acaba por dificultar a conexão desses conceitos por parte dos estudantes.

Podemos perceber por meio das pesquisas supracitadas que o aprendizado do conceito científico de densidade é complexo. Essa complexidade advém das diferentes facetas do conceito e, assim como apontam Rossi et. al., (2008), de seu ensino fragmentado, com os 
elementos necessários para a compreensão ampla da densidade sendo ensinados muito após a parte de a definição ter sido vista e sem a realização da conexão entre os conteúdos. As pesquisas apontam que os estudantes aprendem algo sobre densidade, geralmente relacionado à fórmula da razão da massa pelo volume. Contudo, a parte referente à estrutura química geralmente fica negligenciada no processo.

Tendo em vista a complexidade do conceito e as diferentes formas de expressar o entendimento sobre ele, nossa expectativa é que devem existir níveis de entendimento diferenciados. Assim, nosso objetivo neste trabalho é apresentar o processo de construção e validação de uma taxonomia para o conceito científico de densidade baseada na noção de perfil epistemológico de Bachelard. A explicitação desses níveis por meio de um sistema categórico teoricamente embasado tem potencial para: i) informar a prática de ensino do professor de química ao longo do ensino médio, ii) auxiliar na consolidação de melhores formas de acesso ao entendimento de conceitos científicos.

Nas seções seguintes apresentaremos discussões sobre as contribuições da abordagem do perfil epistemológico para a educação em ciências.

\section{ESTUDOS ACERCA DA CONSTRUÇÃO DE CONCEITOS CIENTÍFICOS}

Com relação à apropriação dos conceitos científicos por parte dos estudantes da educação básica, um modelo que muito influenciou a pesquisa em Educação em Ciências recentemente, foi o modelo de mudança conceitual (MMC) (VILLANI, 1992; MARTINS, 2004; diSESSA, 2006). Esse modelo foi um passo importante, já que partia do pressuposto de que os estudantes tinham explicações próprias para os fenômenos e que essas deveriam ser consideradas no momento da instrução (diSESSA, 2006), refutando a ideia do aluno como uma tábula rasa sem conhecimento algum. Nesse sentido, a ideia de instrução visando aquisição foi substituída pela ideia da mudança conceitual.

No entanto, de acordo com diSessa (2006) no início dos estudos acerca da mudança conceitual, grande parte dos pesquisadores considerava que as ideias dos estudantes eram coerentes e integradas, não restando ao professor outra saída senão discutir com os alunos as suas ideias, e os convencer a aceitar as ideias dos cientistas. Ainda segundo o autor, após algum tempo e várias pesquisas, uma visão diferente surgiu e se tornou bastante influente, a de que ao invés de um corpo coerente inteiro, as ideias dos alunos consistiam em muitos elementos fragmentados, quase independentes. Essa mudança na visão acerca das ideias dos estudantes constituiu um divisor de águas na pesquisa em mudança conceitual.

Os autores do MMC buscaram estabelecer uma associação entre "padrões de mudança conceitual" na ciência e na aprendizagem, através dos conceitos de "assimilação" e 
"acomodação", que podem ser compreendidos como as duas fases na mudança conceitual na aprendizagem (MARTINS, 2004). No entanto, após a aplicação e averiguação de limitações, o modelo sofreu críticas principalmente quanto à questão epistemológica.

Villani (1992) caracteriza a mudança conceitual como um processo demasiadamente complexo e longo, que envolve progressivamente maiores níveis de abstração. Ainda segundo o autor, durante essa passagem haveria ainda a existência de modelos "espontâneos" que seriam empregados fora do âmbito da escola.

Outro pesquisador que se debruçou sobre a temática da construção de conceitos científicos por parte dos estudantes foi Mortimer (1996). Esse autor apresentou à comunidade brasileira de pesquisa em ensino a perspectiva do perfil conceitual, derivada da noção do perfil epistemológico de Bachelard (1979).

Segundo Mortimer (1996) a noção de perfil conceitual apresenta algumas distinções com relação à noção Bachelardiana, dentre elas podemos citar: a diferenciação entre aspectos ontológicos e epistemológicos de cada uma das doutrinas filosóficas do perfil; e a não determinação dos níveis pré-científicos pelas escolas filosóficas de pensamento e sim pelos compromissos epistemológicos e ontológicos dos indivíduos, fortemente influenciados pela cultura.

Assim, ainda segundo o autor, o perfil conceitual seria "um sistema supra-individual de formas de pensamento que pode ser atribuído a qualquer indivíduo dentro de uma mesma cultura" (MORTIMER, 1996, p.34). De forma que, cada pessoa apresentaria um perfil distinto para cada conceito, mas as categorias das diferentes zonas do perfil conceitual seriam independentes do contexto, sendo as mesmas dentro da mesma cultura (MORTIMER, 1996).

Concordamos com Martins (2004) e Souza Filho (2009) que a distinção entre as características ontológicas e epistemológicas de cada zona do perfil se encontra presente na proposta de perfil epistemológico de Bachelard, assim como o sistema supra-individual de formas de pensamento, no qual as categorias seriam dependentes do contexto.

Decidimos adotar a noção do perfil epistemológico neste trabalho, a partir da qual a aquisição de conhecimento pelos estudantes não deve ser vista no sentido apontado por diSessa (2006), de substituição de explicações, pois consideramos que fora do contexto escolar os estudantes continuarão a se valer de explicações não científicas para a maioria dos fenômenos. Defendemos que o ensino não visa necessariamente que os alunos abandonem por completo as explicações de que dispõem, mas que saibam quando utilizar uma e outra.

Desse modo, com o ensino, o leque de conhecimentos dos estudantes irá aumentar, e espera-se que eles tenham autonomia para decidir quando utilizar a versão científica e quando usar a versão "simplista", que no perfil epistemológico equivale ao realismo ingênuo. Ou seja, 
não consideramos necessariamente que haja uma mudança conceitual, visto que cientistas se utilizam de zonas epistemológicas diversas no seu dia a dia (BACHELARD, 1979). Nesse sentido, o ensino de ciências pode se pautar em instrumentalizar os estudantes nas diversas zonas do perfil epistemológico para que eles possam transitar entre elas a depender da necessidade do contexto.

\section{O TRABALHO DE BACHELARD E SUAS CONTRIBUIÇÕES PARA O ENSINO DE CIÊNCIAS}

Halmenschlager e Gehlen (2009) fizeram um levantamento em periódicos nacionais visando apresentar as articulações entre as concepções do filósofo Gaston Bachelard e a pesquisa em Ensino de Ciências no Brasil. As autoras analisaram artigos publicados em cinco periódicos da área de Ensino de Ciências, no período de janeiro de 2000 a setembro de 2008, encontrando um total de onze trabalhos relacionados ao tema.

A análise indicou que mais da metade desses trabalhos mencionava o referencial teórico de Bachelard para realizar articulações com o processo de ensino e aprendizagem. Sob esta ótica, a pesquisa apontou que alguns autores têm trabalhado com a apropriação do referencial teórico de Bachelard para analisar as concepções dos estudantes acerca de determinados conceitos. As autoras citam como exemplo, os seguintes estudos:

i) Amaral e Mortimer (2001) que trabalharam com as concepções de estudantes sobre o conceito de calor, valendo-se da noção de obstáculo epistemológico;

ii) Da Silva Júnior et. al., (2007) que abordaram a perspectiva de perfil epistemológico do conceito de tempo enquanto representação social de licenciandos de alguns cursos da Universidade Federal Rural de Pernambuco. Os autores valeram-se do referencial teórico de Bachelard para identificar o perfil epistemológico dos estudantes em relação ao conceito de tempo, e concluíram que a representação social deles sobre esse conceito está vinculada ao senso comum, não havendo sistematização científica.

iii) Martins e Paca (2005) que se apropriaram das noções de obstáculo epistemológico e de perfil epistemológico para analisar as concepções de tempo de estudantes de ensino fundamental e médio. Os autores salientam que tais noções foram extremamente significativas, pois permitiram não apenas o elencar das concepções alternativas dos estudantes, mas também o estabelecimento de uma estrutura para elas.

Para além do levantamento realizado por Halmenschlager e Gehlen (2009), podemos citar: i) o trabalho de Buscatti Junior (2014) no qual o autor traçou o perfil epistemológico do 
conceito de espaço de licenciandos em Física; ii) o estudo de Muchenski e Miquelin (2015) com estudantes do sétimo ano do ensino fundamental no qual a partir de uma sequência didática experimental os autores buscaram potencializar os perfis epistemológicos dos alunos; e iii) o trabalho de Trevisan e De Andrade Neto (2016), em que os autores construíram os perfis epistemológicos de licenciandos em Física visando compreender suas visões acerca da dualidade onda-partícula em Mecânica Quântica.

Já no âmbito internacional, Roger (2015) utilizou o trabalho de Bachelard para desenvolver uma ferramenta metodológica baseada no perfil epistemológico, visando permitir o desenvolvimento da aprendizagem profissional numa perspectiva além do aprendizado técnico de uma profissão. Blanquet e Picholle (2016) se valeram da noção de perfil epistemológico para investigar as concepções de ciências de professores primários franceses.

A utilização da teoria de Bachelard em pesquisas que buscam compreender o processo de aprendizagem se baseia nos parâmetros apresentados por essa teoria para interpretação de conteúdos formais, dentre os quais o conhecimento científico. De acordo com Lopes (1993), a noção de ruptura no conhecimento científico apontada por Bachelard pressupõe "uma nova forma de compreender toda a história do conhecimento científico. A partir da recorrência histórica, o desenvolvimento do conhecimento científico passa a ser compreendido por constantes rupturas: tanto na sucessividade quanto na simultaneidade temporal" (LOPES, 1993 p. 267)

Durante o processo histórico de construção de qualquer conceito científico, muitos obstáculos tiveram que ser superados pelos cientistas. O conhecimento acerca dos conceitos é dependente das tecnologias disponíveis da época, Bachelard já apontava que a Química se transformou em uma ciência realizada com o suporte de uma fenomenotécnica ${ }^{2}$. Pensando especificamente no conceito científico de densidade, durante muitos séculos tudo que se sabia pertencia à zona empirista do perfil epistemológico, visto que ainda não havia qualquer instrumento que permitisse fazer inferências sobre o arranjo dos átomos.

Dadas as contribuições da noção do perfil epistemológico para a pesquisa em educação e para a diferenciação epistemológica das várias facetas dos conceitos científicos, consideramos que a utilização das doutrinas filosóficas do perfil epistemológico pode auxiliar na compreensão da construção do conceito científico de densidade por parte dos estudantes da

2

Segundo Lopes (1993) a primeira obra em que Bachelard definiu o conceito de fenomenotécnica é A formação do novo espírito científico e a partir daí torna-se completa sua harmonia com a ciência contemporânea. A autora afirma que o termo surge na necessidade de Bachelard de encontrar "outros conceitos além dos conceitos ' visuais' para montar uma técnica do agir-cientificamente-no-mundo e para promover a existência, mediante uma fenomenotécnica de fenômenos que não estão naturalmente-na-natureza" (BACHELARD, 1986, p. 137, apud LOPES, 1993). 
educação básica. Assim como afirmou Bachelard (1979), defendemos que um mesmo conceito adquire configuração e significado a depender da doutrina filosófica sob a qual ele é visto.

Bachelard propôs a noção de perfil epistemológico para conceituar as diferentes formas pelas quais os sujeitos entendem e lidam com a realidade. $\mathrm{O}$ perfil epistemológico consiste em zonas, as quais Bachelard chama também de doutrinas filosóficas ou níveis. Elas variam da mais comum na cultura diária, o realismo ingênuo, passando pelo empirismo, que está relacionado a técnicas de medida com instrumentos, até os racionalismos (racionalismo tradicional ou clássico, racionalismo completo e racionalismo discursivo), estabelecidos por meio de modelos e conceitos abstratos que impõem uma ordem de causalidade teórica na compreensão da realidade. Cada zona é epistemológica e ontologicamente caracterizada. Cada zona se distingue das demais e uma nova zona não pode ser alcançada por adição de conhecimento à zona anterior. $\mathrm{O}$ alcance de uma nova zona se dá através de rupturas.

Em seu trabalho Bachelard utiliza como exemplo diferentes modos de conceituar a definição de massa de seu próprio perfil epistemológico. Ele propõe uma autoanálise de seu perfil para conceituar a massa, e através desse exercício demonstra como as diferentes zonas (doutrinas filosóficas) interagem.

Nesse sentido, podemos estabelecer o entendimento dos estudantes sobre o conceito de densidade através de um questionário que enquadre suas respostas nas zonas do perfil epistemológico. Esse enquadramento é um passo importante para informar ações didáticas apropriadas que visem auxiliar os estudantes a alcançar entendimento sobre todas as dimensões epistemológicas do conceito.

Outro resultado dos estudos de Bachelard acerca do progresso do conhecimento científico foi a caracterização do conceito de obstáculo epistemológico. Segundo o filósofo, a questão do conhecimento deve ser analisada em termos de obstáculos, e a superação desses obstáculos é o que permite o avanço do conhecimento (BACHELARD, 1979).

Se a superação dos obstáculos leva ao avanço do conhecimento, Bachelard aponta que este nunca é definitivo. O autor trabalha então com o conceito de pluralismo filosófico que permite a coexistência de diferentes fases da evolução filosófica, que caminham no sentido de um aumento de coerência racional.

A noção de perfil epistemológico se baseia na existência desse pluralismo de doutrinas filosóficas. O indivíduo agente dispõe de um leque de doutrinas filosóficas que se referem a como ele mobiliza e compreende um determinado conceito em contextos distintos de produção, comunicação e interpretação de significados. De modo que, um mesmo sujeito 
pode apresentar fases de evolução diferentes a depender do conceito e do contexto discursivo que aciona as distintas fases de evolução do conceito.

Bachelard afirma que um conhecimento mais profundo é sempre acompanhado de uma abundância de razões coordenadas e que quanto mais próximo se está do realismo, menor será a presença de fatores racionais. Assim sendo, quanto mais se avança no pensamento científico, maior será o papel das teorias. O autor considera "o progresso científico como uma hierarquia de conhecimentos, no seu aspecto especificamente intelectual" (BACHELARD, 1979, p. 12).

Sob essa perspectiva teórica e considerando a problemática levantada, neste estudo traçamos uma taxonomia baseada na noção de perfil epistemológico para acessar o entendimento dos estudantes do ensino médio sobre o conceito de densidade. Ao amparar nossa investigação nessa perspectiva teórica, esperamos contribuir para o esclarecimento sobre como se dá a construção desse conceito por parte dos estudantes. Para tanto, a seguir apresentamos como caracterizamos os diferentes níveis de entendimento do conceito científico de densidade de acordo com as zonas do perfil epistemológico proposto por Bachelard.

\section{Densidade - Realismo Ingênuo}

Ao discorrer sobre essa zona do perfil epistemológico, Bachelard (1979) afirma que ela é caracterizada pelo imediatismo na construção de afirmações, apreciação visual, uso inconsistente de teorias fragmentadas - não sistemáticas e locais - e uma falta quase completa de generalização. Utilizando o conceito de massa como exemplo, afirma que para o realismo ingênuo, a massa é algo grande, com volume, algo que se torna quantidade se é grande o suficiente.

Pensando no conceito científico de densidade, consideramos que para o realismo ingênuo a densidade é muitas vezes confundida com peso. O senso comum nos brinda com essa relação, tanto que estudantes no início da aprendizagem sobre densidade utilizam expressões como "é muito pesado por seu tamanho" para se dizer que um objeto é denso (FASSOULOPOULOS et. al., 2003). Analogamente ao conceito de massa, denso seria algo pesado o suficiente, mais especificamente para sólidos e no caso de líquidos, denso equivaleria a um líquido viscoso.

Nessa zona do perfil caberiam afirmações cotidianas que associam erroneamente densidade a volume e a massa. Por exemplo, não é incomum encontrar pessoas que afirmam veementemente que um litro pesa um quilo; essa afirmação indica que o indivíduo não consegue utilizar o conceito de densidade para essa situação (pode até ser que em situações 
mais explícitas ele consiga). De modo que esse nível, em uma escala evolutiva, pode ser tomado como ponto de partida para construção do conceito científico de densidade.

Outro exemplo é o caso da associação de densidade ao peso, como no caso de pessoas que não levam em consideração o material ou a substância em questão, mas que relacionam o termo denso a algo possuidor de massa. Essa associação indica que as pessoas podem ter uma noção de que densidade se relaciona de algum modo com um aglomerado que tem massa.

Pensando no caso da flutuação de um sólido em um líquido, amparados por essa zona do perfil, os indivíduos explicam que o material flutua por ser mais leve que o outro. Essa afirmação evidencia a confusão ou desconhecimento do termo densidade e sua substituição pela palavra "leve".

O uso da terminologia "denso" por outras disciplinas - como a literatura ao falar sobre a densidade poética de um texto, afirmando que ele é "denso" - é outro fator complicador que pode acarretar confusão quando se trata do conceito científico de densidade. Porque no sentido metafórico, comumente não se diz pouco denso ou muito denso. Usa-se apenas a palavra "denso", que por si só significa muito denso. Esse uso, que inclusive é a definição de "denso" no dicionário, acarreta a falsa ideia de que a densidade é uma característica relevante apenas para aqueles corpos ou materiais que apresentam valores elevados de densidade.

\section{Densidade - Empirismo}

Ao falar sobre essa zona do perfil epistemológico, Bachelard afirma que ela "corresponde a um emprego cautelosamente empírico, a uma determinação objetiva e precisa" (BACHELARD, 1979 p. 15). Salienta que, no caso de seu exemplo, o conceito de massa, está ligado à utilização da balança. Beneficia-se imediatamente da objetividade instrumental. Assim, podemos pensar no empirismo como uma prática técnica instrumental dirigida e realizada a partir de experiências concretas, com objetos que podem ser medidos, pesados, comparados e facilmente visualizados.

Bachelard afirma que a balança precede sua teoria, pois é evidente que ela foi utilizada muito antes que se conhecesse a teoria da alavanca. Algo muito diferente do que já acontecia na Física de sua época. Pensando no caso do conceito científico de densidade, percebemos que sua definição precede sua teoria explicativa. Não é fácil encontrar registros do uso da densidade anteriores ao famoso experimento de Arquimedes na determinação da densidade da coroa do rei. No entanto, o matemático grego Arquimedes de Siracusa viveu entre 287 e 212 antes de Cristo, muito antes de existirem instrumentos capazes de estudar as 
estruturas dos materiais e as ligações moleculares dos líquidos, ou seja, de haver uma teoria capaz de explicar por que diferentes materiais e substâncias apresentam valores distintos de densidade.

Nesse sentido, consideramos que nessa zona do perfil enquadram-se aquelas conclusões que são possíveis de se obter por meio de experiências simples, como as relações de flutuação entre sólidos e líquidos; e ordem de disposição entre líquidos de densidades diferentes. Para que o estudante consiga entender relações dessa natureza é necessário o conhecimento de que objetos/substâncias menos densos flutuam em outras mais densas e conhecer ou poder consultar, como geralmente ocorre em provas, os valores das densidades das substâncias envolvidas.

Também por meio do uso de alguns instrumentos como a balança e um recipiente com água (para medir o volume de sólidos como supostamente fez Arquimedes) e o uso da razão da massa pelo volume, é possível determinar o valor da densidade de um corpo estando ele no estado sólido ou líquido.

Nesse caso o uso da equação $(\mathrm{d}=\mathrm{m} / \mathrm{v})$ para o cálculo de densidade não exige muita abstração, pois a dependência do mundo empírico aos quais os elementos estão ligados é mantida, a equação se faz necessária porque densidade é uma medida relacionada à massa e volume.

No empirismo a faceta do conceito científico de densidade que surge é a de sua definição. Densidade é vista como uma propriedade intrínseca da substância que pode ser facilmente determinada por meio de experimentos simples. No entanto, ainda não há explicação para o porquê de determinada substância apresentar tal valor de densidade.

\section{Densidade - Racionalismo Tradicional}

Ao explicar este terceiro aspecto, Bachelard afirma que esse paradigma se constituiu com o nascimento da mecânica racional de Newton, no final do século XVII. Enfatizando que à utilização simples e absoluta de uma "noção segue-se a utilização correlativa das noções. A noção de massa define-se então num corpo de noções e já não apenas como um elemento primitivo de uma experiência imediata e direta" (BACHELARD, 1979, p. 16) Bachelard (1979) explica que antes de Newton, a massa era estudada no seu ser, como quantidade de matéria e depois de Newton ela passou a ser estudada num devir dos fenômenos, como um coeficiente de devir.

Pensando no conceito de densidade, que no empirismo é estabelecido por procedimentos técnicos de medida associados ao uso da razão da massa pelo volume, neste novo paradigma (racionalismo tradicional), a densidade é interpretada por teorias, as quais 
explicam a estrutura interna de um material, seja ela cristalina, atômica ou molecular. Assim, densidade passa a ser compreendida em um corpo de noções.

Por exemplo, para se determinar a densidade de um elemento químico, usa-se a massa que corresponde ao átomo-grama, que significa a massa expressa em gramas equivalente à massa atômica do elemento. Considera-se para efeitos de cálculo o volume ocupado por um átomo-grama, este que, por sua vez, depende do tamanho de cada átomo assim como de seus arranjos em suas respectivas substâncias simples (RUSSELL, 1994). No caso de substâncias no estado líquido, a densidade se relaciona com as forças intermoleculares que atuam na substância. Já no estado gasoso, a densidade se relaciona com a massa molecular do gás. Sendo que nos três casos a temperatura influencia a densidade.

Assim sendo, podemos perceber que nesse paradigma densidade é destrinchada em seus agentes causadores, seu valor é uma consequência da distribuição das partículas no espaço, além de depender da temperatura e da pressão (no caso de gases). Assim como afirmou Bachelard, as doutrinas filosóficas mais evoluídas englobam o conhecimento das anteriores. A densidade como um fenômeno que se apresenta no racionalismo tradicional carrega consigo a teoria capaz de explicá-la como um fato que se apresenta no empirismo.

\section{AS DIFERENTES DOUTRINAS FILOSÓFICAS PARA O CONCEITO CIENTÍFICO DE DENSIDADE}

Em seu trabalho, Bachelard (1979) usou o exemplo de seu perfil epistemológico para o conceito de massa para explicar como o conceito adquire várias configurações para um mesmo indivíduo. Neste mesmo trabalho, o autor salientou que nem todos os conceitos teriam todas as zonas do perfil. Em nosso trabalho, considerando o que se ensina sobre o conceito científico de densidade na disciplina de Química na educação básica, consideramos que o conhecimento pode ser abarcado pelas zonas do empirismo e do racionalismo tradicional (duas primeiras zonas científicas do perfil). Nesta pesquisa não nos debruçamos sobre todo o conhecimento acerca desse conceito, principalmente aqueles ensinados nos cursos superiores, como Química e Física, por exemplo.

\section{A TAXONOMIA}

A fim de segmentar todas as nuances do conteúdo de densidade ensinado na educação básica de acordo com as zonas do perfil epistemológico de Bachelard, nos baseamos nas orientações curriculares para o ensino médio (BRASIL, 2006). No quadro 1 (página 113, na seção de conhecimentos de Química) que versa sobre os conhecimentos químicos, habilidades e valores da base comum, o termo densidade aparece na parte de Propriedades 
das substâncias e dos materiais, o tópico com o termo cita a "compreensão do conceito de densidade e solubilidade e a sua dependência com a temperatura e com a natureza do material".

Ao longo de todo o documento, a palavra densidade em si, aparece apenas em dois momentos, no quadro 1 que explicitamos acima e na página 76 quando o termo aparece ao lado da aceleração como sendo uma grandeza formada por relações entre outras.

A partir dos pressupostos da noção do perfil epistemológico, das orientações curriculares para o ensino médio e com base na experiência da primeira autora como professora de Química da educação básica, dividimos o entendimento do conceito de densidade de acordo com as diferentes doutrinas filosóficas. A hierarquia dentro de cada um dos níveis foi estabelecida empiricamente por meio da aplicação de um questionário para estudantes que já haviam estudado o conteúdo.

Nossa intenção em estabelecer o conceito de densidade a partir das zonas do perfil epistemológico de Bachelard foi a de explicitar as diferenças qualitativas que existem nas várias facetas que o conceito pode assumir. No ensino de Química na educação básica muitas vezes essas diferenças não são explicitadas, o que pode dificultar os estudantes no processo de aprendizagem do conceito. Como estamos trabalhando com as facetas escolarizadas do conceito de densidade, não incluímos a zona do realismo ingênuo em nossa sistematização.

Tabela 1: Categorização dos níveis de entendimento em ordem hierárquica do conceito de densidade nas zonas do empirismo e do racionalismo tradicional

\begin{tabular}{|c|c|}
\hline \multicolumn{1}{|c|}{ Empirismo (E) } & Racionalismo tradicional (RT) \\
\hline $\begin{array}{l}\text { 1) } \begin{array}{l}\text { Saber operar com a fórmula } \\
\text { de densidade d=m/v }\end{array} \\
\text { 2) } \begin{array}{l}\text { Saber a relação entre } \\
\text { densidade e flutuação }\end{array}\end{array}$ & $\begin{array}{l}\text { 1) } \\
\text { Saber que a densidade é dependente da } \\
\text { configuração molecular ou cristalina } \\
\text { dos átomos ou moléculas que compõe } \\
\text { a substância }\end{array}$ \\
3) $\begin{array}{l}\text { Saber calcular a densidade de } \\
\text { misturas/ soluções }\end{array}$ & 2) $\begin{array}{l}\text { Saber calcular a densidade utilizando } \\
\text { elementos abstratos/teóricos }\end{array}$ \\
4) $\begin{array}{l}\text { Identificar a variação no valor } \\
\text { de densidade de misturas por } \\
\text { meio da adição de solutos } \\
\text { e/ou solventes }\end{array}$ & 3) $\begin{array}{l}\text { Saber relacionar o conceito com forças } \\
\text { intermoleculares/ polaridade para } \\
\text { substâncias puras }\end{array}$ \\
& 4) $\begin{array}{l}\text { Saber relacionar o conceito com forças } \\
\text { intermoleculares/ polaridade para } \\
\text { misturas }\end{array}$ \\
\hline
\end{tabular}

Fonte: Autores 


\section{Estabelecimento das hierarquias dentro das zonas}

Primeiramente a Tabela 1 foi construída a partir dos conhecimentos do conceito que são ensinados no ensino médio e as características apontadas por Bachelard em A filosofia do Não, para cada uma das doutrinas filosóficas.

Posteriormente foi construído um questionário aberto, contendo 24 questões que abrangiam o conteúdo de densidade ensinado no ensino médio. Algumas dessas questões foram retiradas na íntegra de sites escolares sobre densidade nos quais estudantes postam suas dúvidas, algumas foram adaptadas desses sites, uma foi adaptada do estudo de Rossi et. al., (2008) e outras foram elaboradas pelos autores. No questionário havia pelo menos um item referente a cada um dos níveis elencados na Tabela 1, além de questões básicas sobre relações entre massa e volume que não foram utilizadas para o estabelecimento das hierarquias nesse estudo, e sim como contextualizadoras para os estudantes na ocasião da resolução.

Foram escolhidas questões de diversos níveis de dificuldade, adaptamos questões contextualizadas no modelo do ENEM para se tornarem questões discursivas, também utilizamos questões mais simples e diretas, e questões que pudessem capturar equívocos com relação ao conceito científico de densidade por associação do conceito ao peso ou volume, por exemplo, o que se configuraria uma resposta no nível do realismo ingênuo de acordo com o perfil epistemológico.

Além dessas 24 questões, outras duas foram elaboradas visando medir o grau de avanço dos estudantes na construção das zonas de seus perfis epistemológicos. Uma delas, uma questão em cadeia, onde a resposta da alternativa anterior é usada na posterior; e uma situação problema. Nosso intuito com a aplicação do questionário era o de estabelecer empiricamente uma hierarquia dentro das zonas do nosso sistema categórico.

Para a correção das questões houve uma diferenciação entre as pertencentes ao nível do empirismo e algumas do racionalismo. As questões empíricas foram corrigidas em formato dicotômico, atribuímos escore 2 para as certas e 0 para as erradas. Já algumas questões do racionalismo permitiam uma resposta parcialmente correta no nível empírico, para essas questões creditamos escore 2 para a resposta no nível do racionalismo, 1 para o empirismo e 0 para respostas erradas ou a não resolução da questão.

Devido à quantidade de questões e ao fato delas serem discursivas, optamos em dividir as 24 questões em dois questionários, modelo A e modelo B. Em ambos deixamos as questões em forma de cadeia e a situação problema, de modo que cada questionário era composto 14 questões. A divisão do questionário visou evitar que a quantidade de questões desestimulasse os estudantes na hora da resolução. 
O questionário foi aplicado para 38 alunos que já haviam estudado o conteúdo de densidade do segundo e terceiro anos de um colégio federal na região metropolitana de Salvador, a coleta ocorreu no final do ano de 2017. Apresentamos abaixo quatro questões ${ }^{3}$ utilizadas na coleta que foram elaboradas pelo grupo de pesquisa:

Tabela: 2- Questão em cadeia - presente nos dois questionários

Considere três substâncias 1,2 e 3, com as respectivas massas e volumes: $\mathrm{m}_{1}$ igual a 70 gramas, $\mathrm{m}_{2}$ igual a 35 gramas e $\mathrm{m}_{3}$ igual a 33 gramas; $\mathrm{V}_{1}=50 \mathrm{~mL}, \mathrm{~V}_{2}=50 \mathrm{~mL}$ e $\mathrm{V}_{3}$ $=30 \mathrm{~mL}$. Utilize o verso da folha para realizar os cálculos.

a) Calcule o valor da densidade de cada uma das substâncias (E1)

b) Suponha que as três substâncias sejam líquidas e imiscíveis entre si, qual seria a ordem em que elas ficariam quando colocadas em uma mesma proveta? (E2)

c) Suponha agora que a substância que ficou no meio da proveta misteriosamente se misture com a que ficou na parte superior, qual seria a densidade dessa mistura? (E3)

d) Se a esta mistura fosse adicionado 5 gramas de um soluto não volátil, ela continuaria com a mesma densidade? Se não, calcule a valor de sua nova densidade. (E4)

e) Tomando como referência a mistura com as 5 gramas de soluto não volátil dissolvidas, o que você pode dizer sobre as distâncias entre as moléculas/íons que compõe a mistura? Estabeleça uma comparação entre as distâncias entre as moléculas da substância X que tem densidade $0,8 \mathrm{~g} / \mathrm{mL}$. (RT1)

f) Suponha que na substância $X$ as forças intermoleculares existentes são do tipo dipolo-dipolo, nesse caso, se tomarmos como referências apenas a distância entre as moléculas da mistura, como se ela fosse uma substância só, qual teria que ser a força intermolecular existente nela? (RT3)

g) Qual será o volume de $50 \mathrm{~mL}$ de álcool quando misturado com $50 \mathrm{~mL}$ de uma substância com a força intermolecular que você respondeu na letra f? (RT4)

h) Considere que o volume que você calculou na letra g, equivale a dez vezes a massa molecular de um gás. Calcule a densidade absoluta desse gás quando submetido a 1,0 atm de pressão e $47^{\circ} \mathrm{C}$. (RT2)

Fonte: Autores

Tabela: 3- Situação problema - presente nos dois questionários

Imagine a seguinte situação: Foram esquecidas duas provetas contendo cada uma um líquido e um pequenino cubo em cima de uma bancada em um laboratório de Química. Uma estudante muito curiosa se deparou sozinha no laboratório com essa situação e começou a realizar os seguintes testes.

- Colocou o cubo dentro de uma das provetas e observou que ele flutuou.

- Colocou o cubo dentro da outra proveta e viu que ele afundou.

- Na tentativa de retirar o cubo da segunda proveta ela despejou todo o líquido dessa na outra e observou que os dois líquidos se misturaram. No entanto a estudante ficou intrigada ao perceber que o volume dos dois líquidos juntos era menor do que a soma

3 Entre parêntesis na frente de cada item está sua relação com a Tabela 1 
deles quando estavam separados.

Com relação às experiências realizadas pela estudante, o que você pode dizer sobre:

a) densidade dos líquidos e do cubo (E2)

b) As forças intermoleculares que agiam sobre os dois líquidos. (RT3, RT4)

Fonte: Autores

Considere os objetos abaixo, com suas respectivas massas e volumes e responda:

\section{Objeto A \\ Massa igual a $40 \mathrm{~g}$ \\ Volume igual a $100 \mathrm{~mL}$}

\section{Objeto D}

Massa igual a $80 \mathrm{~g}$

Volume igual a $160 \mathrm{~mL}$

\section{Objeto B}

Massa igual a $70 \mathrm{~g}$

Volume igual a $20 \mathrm{~mL}$

\section{Objeto E}

Massa igual a $136 \mathrm{~g}$

Volume igual a $10 \mathrm{~mL}$

a) Qual deles é o maior?

b) Qual deles é o mais pesado?

c) Qual deles é o mais denso? (E1)

d) Quando colocados em água (densidade igual a $1 \mathrm{~g} / \mathrm{mL}$ ) quais flutuam e quais afundam? (E2)

Figura: 1 - Questão presente no questionário modelo A

Fonte: Autores

Tabela: 4- Situação problema - presente nos dois questionários

Explique por que cubos de gelo são menos densos que água sendo que ambos são formados por moléculas de $\mathrm{H}_{2} \mathrm{O}$. (RT1)

Fonte: Autores

\section{ANÁLISES E RESULTADOS}

Como os estudantes que responderam ao questionário já haviam estudado o conteúdo de densidade, solicitamos que antes de começarem a responder aos itens fizessem uma autoavaliação do quanto sabiam sobre densidade. A questão apresentava uma escala de 0 a 4 , em ordem crescente de conhecimento sobre o tema e instruía os alunos a marcar o número que julgassem corresponder ao seu conhecimento sobre densidade.

Metade dos estudantes (19 dos 38) indicaram que seu conhecimento em relação à densidade correspondia ao número 2. Contudo, não houve relação entre suas autoavaliações e seus desempenhos no teste, o que nos leva a pressupor que em geral os alunos não sabem exatamente o quanto dominam o tema. Por exemplo, dois estudantes marcaram que seu conhecimento sobre densidade equivalia ao número 4, ou seja, eles acreditavam que 
dominavam todo o conteúdo. Contudo um deles obteve pontuação equivalente a $57 \%$ do valor do teste e o outro $16 \%$. O maior escore obtido foi de um estudante que não declarou seu conhecimento e obteve pontuação correspondente a 59,6\% do teste.

A falta de consciência acerca de seus conhecimentos sobre o conceito de densidade já havia sido apontada na pesquisa de Rossi et. al., (2008). Contudo, em nosso estudo os alunos declararam saber menos em suas autoavaliações do que os alunos que participaram do estudo de Rossi et. al., (2008). Esse fato pode ser devido ao estudo das autoras ter envolvido também alunos de cursos superiores.

Em relação à questão que elaboramos em forma de cadeia, onde o item seguinte dependia da resposta ao item anterior, o item $a$ que correspondia ao primeiro nível da zona do empirismo, e demandava que os estudantes calculassem valores de densidade a partir da massa e do volume de três líquidos, foi o que teve o maior número de acertos. $\mathrm{O}$ valor encontrado no item $a$ deveria ser utilizado para resolver o $b$, que solicitava que os estudantes previssem a disposição dos três líquidos, os considerando imiscíveis, quando colocados numa mesma proveta, e assim por diante. Os itens $b, c$ e $d$, referentes respectivamente ao segundo, terceiro e quarto níveis do empirismo apresentaram uma ordem decrescente de quantidade de acertos, o que aponta o grau crescente de dificuldade das categorias ao longo da zona.

Os itens $e, f, g$ e $h$, não foram acertados por nenhum dos 38 estudantes que responderam ao questionário. Contudo, alguns alunos escreveram que não estudaram tais conteúdos, ou que não lembravam de ter estudado. Esses itens se referiam à zona do racionalismo tradicional. No entanto, conseguimos obter dados referentes aos níveis dessa zona com as demais questões, portanto, acreditamos que o formato da questão possa ter confundido alguns alunos.

Concernente a nossa questão problema observou-se que o item $a$ que versava sobre o segundo nível do empirismo foi mais acertado que o item $b$ que versava sobre os níveis 3 e 4 do racionalismo tradicional.

Nas tabelas abaixo apresentamos a média de escore de cada um dos itens que se referem ao nosso sistema categórico divididos nos questionários modelo $\mathrm{A}$ e modelo $\mathrm{B}^{4}$. Houve casos em que tivemos mais de um item para a mesma categoria do sistema categórico, por isso optamos em apresentar a média que nos permite estabelecer comparações. Alguns itens foram abandonados após a aplicação, pois eles versavam sobre conteúdos de alguma forma ligados à densidade, mas que não correspondiam a nenhum nível na nossa taxonomia. Desse modo, eles foram utilizados como contextualizadores para os estudantes na ocasião da resolução, mas não correspondiam diretamente ao nosso sistema categórico. Nossa análise

\footnotetext{
${ }^{4}$ Devido à aparente falta de clareza dos itens referentes à zona do racionalismo tradicional na questão em cadeia, eles não foram considerados para o cálculo da média de escore. 
focou nos itens referentes aos entendimentos do conceito científico de densidade nas zonas do empirismo e do racionalismo.

Tabela 5 - Média das pontuações para o questionário modelo A

\begin{tabular}{|l|l|l|}
\hline Nível & Quantidade de itens & Média das pontuações \\
\hline E1 & 2 & 38 \\
\hline E2 & 3 & 31,3 \\
\hline E3 ${ }^{*}$ & 2 & 9 \\
\hline E4 & 1 & 27 \\
\hline RT1 & 1 & 12 \\
\hline RT2 & 2 & 3,5 \\
\hline RT3 & 1 & 1 \\
\hline
\end{tabular}

Fonte: Autores

Tabela 6 - Média das pontuações para o questionário modelo B

\begin{tabular}{|l|l|l|}
\hline Nível & Quantidade de itens & Média das pontuações \\
\hline E1 & 1 & 21 \\
\hline E2 & 1 & 20 \\
\hline E3 & 3 & 9 \\
\hline E4 & 4 & 1,5 \\
\hline RT1 & 1 & 6 \\
\hline RT2 & 2 & 0 \\
\hline RT4 & 1 & 0 \\
\hline
\end{tabular}

Fonte: Autores

Após a correção do questionário modelo A verificamos que os dois itens referentes ao nível E3 exigiam dos estudantes conhecimento de porcentagem, se configurando assim uma questão com um grau de dificuldade maior, pois além do conhecimento sobre densidade o estudante precisava utilizar cálculos envolvendo porcentagem. Assim, optamos por estabelecer a hierarquia para o nível E3 pela análise do questionário modelo $\mathrm{B}$, no qual a questão referente a este nível exigia apenas o conhecimento sobre o conceito de densidade e pela questão encadeada.

Pela análise das tabelas foi possível validar a hierarquia dos níveis dentro das zonas do Empirismo e do Racionalismo Tradicional do Perfil Epistemológico. Sobre a relação entre empirismo e racionalismo, Bachelard escreve: “...o empirismo precisa ser compreendido; o racionalismo precisa ser aplicado... O valor de uma lei empírica prova-se fazendo dela a base 
de um raciocínio. Legitima-se um raciocínio fazendo dele a base para uma experiência" (Bachelard, 1979, p.5).

\section{CONSIDERAÇÕES FINAIS}

A noção do perfil epistemológico oferece uma ordem crescente de generalização e abstração que ocorreu durante o processo de construção do conceito em questão. O seu uso na construção da taxonomia para o conceito científico de densidade construída neste artigo, pode ajudar a esclarecer para professores e estudantes as características das diferentes facetas do conceito.

Bachelard afirma que nem todos os conceitos apresentam todas as doutrinas filosóficas do perfil epistemológico, salienta que existem ciências inteiras, como a Biologia que se estruturam sobre o empirismo, por exemplo. Entretanto, com relação essa afirmação do autor cabe ressaltar que seu trabalho foi escrito antes da Biologia se consagrar enquanto ciência racional com o mapeamento do DNA e a engenharia genética.

É interessante notar que o caminho de evolução histórica de qualquer ciência, se dá através das zonas do perfil epistemológico, em um sentido crescente de abstração e generalização. Sendo assim, neste trabalho nos apoiamos na constituição histórica do conceito científico de densidade, com a finalidade de estabelecer suas características nas zonas do empirismo e do racionalismo tradicional do perfil epistemológico. A partir disso, foi possível validar uma taxonomia hierárquica para o conceito de densidade.

A grade teórica de evolução do conceito de densidade pode ser aplicada por professores e livros didáticos, visando tornar explícitas as habilidades necessárias em cada uma das zonas que caracterizam o conceito. Desse modo, é de grande importância que os conhecimentos que dão embasamento teórico sejam trazidos no momento do ensino de densidade e não abordados em momentos distintos, o que, conforme apontam Rossi et. al., (2008), colabora para dificultar a aprendizagem do conceito de densidade.

Por fim, embasados nos resultados deste estudo, apresentamos um sistema categórico cuja ordem hierárquica de complexidade se sustenta empiricamente, tendo como parâmetro de classificação as zonas do perfil epistemológico de Bachelard para o conceito científico de densidade. Nesse sentido, consideramos importante a continuidade da pesquisa visando informar a produção de material didático que possa orientar professores em suas abordagens de ensino e na orientação epistemológica de suas aulas. A orientação epistemológica pode seguir um grau crescente de complexidade, auxiliando os estudantes a alcançar maior entendimento e consciência sobre o conceito científico de densidade. 


\section{AGRADECIMENTO}

O presente trabalho foi realizado com apoio da Coordenação de Aperfeiçoamento de Pessoal de Nível Superior - Brasil (CAPES) - Código de Financiamento 001.

\section{REFERÊNCIAS}

AL-TARAWNEH, M. H. "The Effectiveness of Educational Games on Scientific Concepts Acquisition in First Grade Students in Science", Journal of Education and Practice, 7(3), pp 31-37, 2016.

AMARAL, E. M., MORTIMER, E. F. Uma proposta de perfil conceitual para o conceito de calor. Revista Brasileira de Pesquisa em Educação em Ciências. Porto Alegre: v.1, n.3, p.5 $-18,2001$.

BACHELARD, G. A Filosofia do Não; In: Os Pensadores. São Paulo: Abril Cultural, p. 0187, 1979.

BLANQUET, E.; PICHOLLE.E. Profil épistémologique des enseignants français du primaire au regard de la science. Cécile de Hosson. 9e Rencontres scientifiques de l'ARDIST, Mar 2016, Lens, France. 2016.

BRASIL, Orientações curriculares para o ensino médio volume 2. Ciências da natureza, matemática e suas tecnologias - Brasília: Ministério da Educação, Secretaria de Educação Básica, 2006.

BUSCATTI JUNIOR, D. A. O perfil epistemológico do conceito de espaço em alunos do curso de licenciatura em física. Dissertação de mestrado em educação para a Ciência Faculdade de Ciências - UNESP, Bauru, 2014.

DISESSA, A.A. A history of conceptual change research: Threads and fault lines. In R.K. Sawyer (Ed.), The Cambridge handbook of the learning sciences (p. 265-281) New York: Cambridge University Press, 2006.

FASSOULOPOULOS, G.; KARIOTOGLU, P.; KOUMARAS, P. Consistent and Inconsistent Pupils'Reasoning about Intensive Quantities: The Case of Density and Pressure, Research in Science Education, v.33, p.71-87, 2003.

HALMENSCHLAGER, K.R., GEHLEN, S. T. Bachelard e a educação em ciências: uma revisão em periódicos científicos brasileiros. In: XVIII SIMPÓSIO NACIONAL DE ENSINO DE FÍSICA, Vitória, 2009.

HASHWEH, M. Z. The complexity of teaching density in middle school, Research in Science \& Technological Education, 2015.

HAWKES, S.J. The concept of density. Journal of Chemical Education, v. 81, n. 1, p.14$15,2004$.

LOPES, A. R. C. Contribuições de Gaston Bachelard ao ensino de ciências. Enseñanza de las Ciencias, Barcelona, Universidade Autônoma de Barcelona, v. 11, n. 3, p. 324-330, 1993. 
MARTINS, A. F. P.; PACCA, J. L. A. O conceito de tempo entre estudantes do ensino fundamental e médio: uma análise à luz da epistemologia de Gaston Bachelard. Investigações em Ensino de Ciências, Porto Alegre - RS, v. 10, n. 3, p. 1 -34, 2005.

MARTINS, A.F.P. Concepções de estudantes acerca do conceito de tempo: uma análise à luz da epistemologia de Gaston Bachelard. Tese de doutorado em Educação - Faculdade de Educação, USP, São Paulo, 2004.

MORTIMER, E. F. Construtivismo, mudança conceitual e ensino de ciências: para onde vamos? Investigações em Ensino de Ciências v. 1, p. 20-39, 1996.

MUCHENSKI, J. C.; MIQUELIN, A. F. Experimentação no ensino de Física como método de aperfeiçoamento do perfil epistemológico dos estudantes do sétimo ano do ensino fundamental. Experiências em Ensino de Ciências V.10, No. 1, 2015.

PIAGET, J. The child's conception of causality. London: Kegan Paul, 1930.

PIAGET, J., INHELDER, B. The Child's Construction of Quantities: Conservation and Atomism, Routledge \& Kegan Paul, London, 1974.

POZO, J.I.; CRESPO, M.A.G. A aprendizagem e o ensino de ciências - do conhecimento cotidiano ao conhecimento científico. 5. ed. Porto Alegre: Artmed, 2006.

ROGER, L. Le profil épistémologique comme outil méthodologique et heuristique pour soutenir le développement de l'apprentissage professionnel en formation. Recherches qualitatives, 34(1), 143-156, 2015a.

ROSSI, A.V.; MASSAROTTO, A.M.; GARCIA, F.B.T.; ANSELMO, G.R.T.; DE MARCO, I.L.G.; CURRALERO, I.C.B.; TERRA, J.; ZANINI, S.M.C. Reflexões sobre o que se ensina e o que se aprende sobre densidade a partir da escolarização. Química Nova na Escola, n. 30, p. 55-60, 2008.

RUSSELL, John B.; Química Geral vol.1, São Paulo: Pearson Education do Brasil, Makron Books, 1994.

DA SILVA JUNIOR, A. G.; TENÒRIO A. C.; BASTOS H. F. B. N. O perfil Epistemológico do conceito de tempo a partir de sua representação social. Ensaio. Pesquisa em Educação em Ciências, v. 9 n.2, p. 1-17, 2007.

SOUZA FILHO, M. P. O erro em sala de aula: subsídios para o ensino do eletromagnetismo. Tese de doutorado em Educação para a Ciência - Faculdade de Ciências - Universidade Estadual Paulista, Bauru, 2009.

TREVISAN, R.; DE ANDRADE NETO, A. S. Uma construção do Perfil Epistemológico de licenciandos em Física acerca da dualidade onda-partícula em Mecânica Quântica, após o uso de bancadas virtuais: um estudo a partir do discurso gestual e verbal. RENOTE. Revista Novas Tecnologias na Educação, v. 14, p. 1, 2016.

VILLANI, A. Conceptual Change in Science and Science Education. Science Education, v. 76, n.2, p. 223-238, 1992.

ZIRBEL, E. Teaching to Promote Deep Understanding and Instigate Conceptual Change. Bulletin of the American Astronomical Society. 38, 1220-1244, 2006. 


\section{SOBRE OS AUTORES}

\section{AUTOR 1.}

Viviane Florentino de Melo é professora da Faculdade de Educação da Universidade Federal da Bahia, Doutoranda do programa de pós-graduação em Ensino, Filosofia e História das Ciências (UFBa). Neste trabalho foi responsável pela escrita do texto, revisão bibliográfica, interpretação do currículo de Química, segmentação do conceito de densidade nas zonas do perfil epistemológico, elaboração e correção dos questionários.

\section{AUTOR 2.}

Amanda Amantes é professora do Instituto de Física da Universidade Federal da Bahia e do programa de pós-graduação em Ensino, Filosofia e História das Ciências (UFBa). Neste trabalho foi responsável pelo desenho metodológico, pela elaboração dos questionários e revisão do texto.

\section{AUTOR 3.}

Rodrigo Drumond Vieira é professor da Faculdade de Educação da Universidade Federal Fluminense. Neste trabalho foi responsável pela segmentação do conceito de densidade nas zonas do perfil epistemológico e revisão do texto. 